\title{
Apresentação
}

Temos a satisfação de apresentar a edição número 17 da revista $D e$ senvolvimento em Questão, vinculada ao Programa de Pós-Graduação Stricto Sensu em Desenvolvimento da Universidade Regional do Noroeste do Estado do Rio Grande do Sul - Unijuí. Com o compromisso de estimular o debate, a reflexão e a socialização de saberes relacionados à questão do desenvolvimento, queremos disponibilizá-la aos colaboradores diretos (autores, avaliadores e membros do conselho editorial), programas e instituições parceiras, bem como ao crescente público que a acessa livremente no portal da Redalyc - Red de Revistas Científicas de América Latina y el Caribe, España y Portugal, coordenada pela Universidad Autónoma del Estado de México (<http:// redalyc.uaemex.mx $>$, ou diretamente em <http://redalyc.uaemex.mx/src/ inicio/HomRevRed.jsp?iGveEntRev=752>).

Conforme anunciado na apresentação da edição anterior, a revista está iniciando o processo de introdução do Serviço de Editoração Eletrônica de Revistas - SEER -, com o qual esperamos dar mais agilidade aos processos de submissão e de avaliação de trabalhos. Pela avaliação da fase inicial da transição, a expectativa é de que a partir da edição de número 18 a revista tenha uma versão impressa e uma versão eletrônica, com um indicativo de que, a partir de 2013, a revista mantenha apenas a versão eletrônica, seguindo a tendência da maioria dos periódicos. Insistimos, entretanto, que a revista continuará a mesma, mantendo a sua linha editorial.

Esta edição de número 17 contempla seis artigos, dois dos quais de autoria de pessoas com vínculo ao curso de Mestrado em Desenvolvimento da Unijuí, três de autores vinculados a outras instituições nacionais e um de autor estrangeiro.

A preocupação em torno de estratégias e políticas de desenvolvimento está presente nos quatro primeiros artigos. No trabalho que abre a edição, Marcos Junior Marini e Christian Luiz da Silva analisam o plano de ação brasileiro no que diz respeito à política de Ciência e Tecnologia e o 
desenvolvimento do país. O moçambicano Tomás Adriano Sitoe, por sua vez, reflete criticamente sobre o alcance da utilização da abordagem dos modos de vida para analisar as estratégias de sobrevivência e de enfrentamento da pobreza no meio rural africano. O meio rural também se constitui o foco de referência do artigo de Vanderlei A. Schwantes, David Basso e Arlindo J. P. de Lima, no qual avaliam as contribuições do Programa Nacional de Fortalecimento da Agricultura Familiar - Pronaf - como uma estratégia possível para a promoção do desenvolvimento rural. O artigo de Cleidson Nogueira Dias, por fim, discute a abordagem dos Arranjos Produtivos Locais - APLs - como uma estratégia de desenvolvimento territorial.

Maria Elizabeth Horn Pepulim, Gregógio Varvakis e Francisco Pereira Fialho discutem em seu artigo sobre a aplicabilidade de muitas das constantes inovações que empresas de telefonia móvel têm disponibilizado ao público em geral, como é o caso da tecnologia $3 \mathrm{G}$, para acesso à Internet por meio de aparelhos celulares.

Finalizando a edição Argemiro Luís Brum, Wylmor Dalfovo e Vitor Benfica analisam a relação entre a expansão da agricultura comercial de grãos e o desmatamento na Amazônia, tomando como referência o município de Sinop, localizado na região Centro-Norte do Mato Grosso.

Esperando que estes trabalhos possam despertar a curiosidade e satisfazer as expectativas dos leitores, a revista Desenvolvimento em Questão agradece a todos os que colaboraram para esta edição - autores, avaliadores, revisores, membros do conselho editorial - ao mesmo tempo em que se coloca à disposição para receber novas contribuições que se proponham a alimentar o debate, tanto no sentido de reforçar ideias, responder criticamente posicionamentos teórico-metodológicos utilizados pelos nossos colaboradores para analisar processos ou situações de desenvolvimento, quanto para agregar novos temas, conceitos ou abordagens que contribuam para alargar e fazer avançar as reflexões sobre o desenvolvimento.

\section{David Basso}

Presidente do Comitê Editorial 